\title{
The role of childhood adversity and prenatal mental health as psychosocial risk factors for adverse delivery and neonatal outcomes: a prospective cohort study
}

\author{
Hlin Kristbergsdottir ${ }^{1}$, Heiddis Valdimarsdottir ${ }^{1}$, ora Steingrimsdottir ${ }^{2}$, Rannveig \\ Sigurvinsdottir ${ }^{1}$, Sigurgrimur Skulason ${ }^{2}$, Linda Lydsdottir ${ }^{1}$, Sigridur Jonsdottir ${ }^{3}$, Halldora \\ Olafsdottir $^{4}$, and Jon Sigurdsson ${ }^{1}$ \\ ${ }^{1}$ University of Reykjavik \\ ${ }^{2}$ University of Iceland \\ ${ }^{3}$ University of Akureyri Iceland \\ ${ }^{4}$ Landspitali
}

February 21, 2021

\begin{abstract}
Objective. To examine the association between adverse childhood experiences (ACE), prenatal common mental disorders (PCMDs) and delivery and neonatal outcomes. Also, to examine the overall effect of ACE and individual ACE subcategories on PCMD diagnosis and obstetric outcomes. Design. Prospective cohort study from pregnancy to birth. Setting. The study was based on an Icelandic cohort study and supplemented with maternal childbirth records from three hospitals in Iceland. Sample. Women recruited in the cohort study who had accessible childbirth records and singleton births $(\mathrm{N}=522)$. Methods. Bayesian SEM was used to test pathways between ACE, PCMD and delivery and neonatal outcomes with probit regression models. Main outcome measures. ACE was assessed with a semi-structured interview. PCMD was diagnosed with the MINI+. Delivery outcomes were defined as pain management during labor and mode of delivery. Neonatal outcomes were defined as small for gestational age (SGA), preterm delivery (PD), Apgar score, fetal distress, and newborn intensive care unit (NICU) admissions. Results. Women having experienced ACE were at increased risk of PCMD $[\beta=.538, \mathrm{p}<.001$, CI: .195-1.154] and PD [ $\beta=.768$, $\mathrm{p}<.05$, CI: $.279-1.007)]$. An indirect association was found between ACE and increased risk of non-spontaneous delivery $[\beta=.054, \mathrm{p}<.05, \mathrm{CI}: .004-.152]$, mediated by PCMD. Identical findings were observed for individual ACE subcategories. Conclusion. The negative impact of ACE on non-spontaneous delivery is mediated by the impact of ACE on PCMD diagnosis suggesting that interventions aimed at decreasing PCMD may reduce the risk of non-spontaneous delivery.
\end{abstract}

\section{Hosted file}

Psychosocial risk factors for adverse delivery and neonatal outcomes.pdf available at https://authorea.com/users/397090/articles/510108-the-role-of-childhood-adversity-andprenatal-mental-health-as-psychosocial-risk-factors-for-adverse-delivery-and-neonataloutcomes-a-prospective-cohort-study

\section{Hosted file}

Title page_Psychosocial risk factors for delivery and neonatal outcomes.pdf available at https://authorea.com/users/397090/articles/510108-the-role-of-childhood-adversity-andprenatal-mental-health-as-psychosocial-risk-factors-for-adverse-delivery-and-neonataloutcomes-a-prospective-cohort-study 


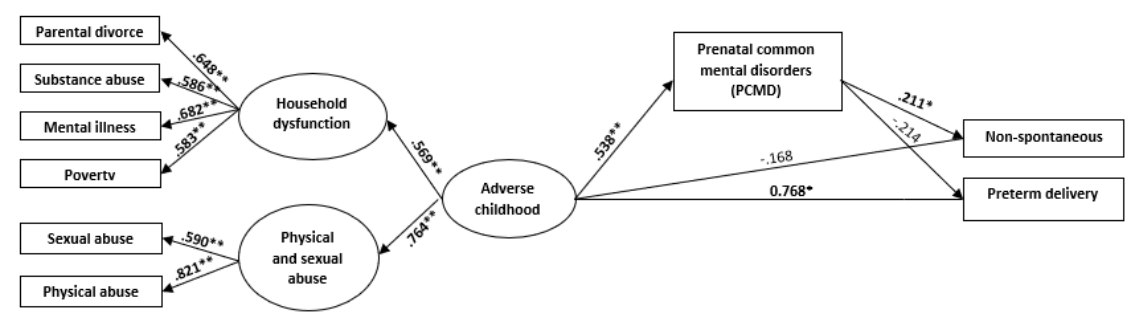

